\title{
The impact of curbside parking regulation on garage demand
}

Albert Gragera*, Universitat de Barcelona, Dept. Política Econòmica, Avda. Diagonal 690, 08034 (Barcelona) Grup de Recerca en Governs i Mercats (GiM), Institut de Recerca en Economia Aplicada (IREA), Universitat de Barcelona. E-mail: albert.gragera@ub.edu (*corresponding autor)

Daniel Albalate, Universitat de Barcelona, Dept. Política Econòmica, Avda. Diagonal 690, 08034 (Barcelona) Grup de Recerca en Governs i Mercats (GiM), Institut de Recerca en Economia Aplicada (IREA), Universitat de Barcelona. E-mail: albalate@ub.edu

ABSTRACT:

Parking regulation is seen as a good option to encourage modal shift in order to tackle congestion and pollution in metropolitan areas. Market-clearing curbside pricing is rarely implemented and policy makers have tended to make off-street parking provision their main tool to address excessive curbside demand. Research devoted to garage parking is far less well developed, even though public authorities provide both curbside and garage parking that compete with privately operated facilities.

In this paper the impact of garage fare and curbside regulation characteristics (fare and type of dedicated spaces) on garage parking demand are investigated. Aggregate occasional and subscribers parking demand is analyzed by means of two different econometric models estimated using a panel from Barcelona's public parking authority (BSM) that covers 34 garage facilities with yearly data for the period 2006-2012.

We find that both demand segments show a negative elasticity to garage fare. Only occasional parkers show a clear substitution effect with a curbside premium (€0.55/hour). Our finding suggests that the actual pricing efficiency gap in Barcelona can range between $€ 0.45$ and $€ 1.05$ due to the mismatch between curbside and garage pricing regimes; for which we propose some policy alternatives. This stresses the need for a single integrated market approach to parking management, in order to overcome market distortions and achieve efficiency. Additionally, our results show that the characteristics of curbside parking spaces (allowance and time limits) play a role in garage demand determination, yet pricing is much more efficient trigger for behavioral change.

Keywords: Parking; Off-street parking; On-street parking; Garage parking; Curbside parking; Parking regulation, Price elasticity

JEL Codes: R41, R48 


\section{Introduction}

Major urban areas have broadly adopted parking regulations and pricing as their main travel demand management tool to tackle excessive traffic demand-related externalities (like congestion and pollution). This tool has relatively low implementation costs, better public acceptance than road pricing, and can be controlled directly by local government (Litman, 2006; Button, 2006; Ison, 2014; and Rye \& Koglin, 2014).

Although parking is a private good (rivalrous and excludable), it is often publicly provided both on-street (curbside) and off-street (in garages) (ITDP, 2010 and 2011). Public provision is justified on the grounds of market distortions: (i) a search externality imposed by drivers cruising for empty spots (excessive curbside demand); and (ii) garages' localized market power that arises from the discrete spacing of lots, due to construction scale economies (Inci, 2015). In order to achieve efficiency in this market, cruising must be eliminated by setting the right fare differential between curbside and garage parking, and by allocating the right quantity of demand to the most suitable lot at each moment (first-best). The fact that users are willing to pay a premium for on-street parking (Kobus et al., 2013) suggests that the curbside fare should be higher than the garage fare, in the presence of a search externality. Thus, if curbside and garage parking strategies are not coordinated, inefficient use of resources is likely to arise. If curbside parking is underpriced, it tends to be congested, slow down through traffic, and cause underutilization of public garages.

However, policy makers have tended to keep prices low and have focused on the expansion of controlled parking zones containing different types of dedicated curbside spaces, with a clear bias towards residential permits (i.e. mixed use or residentexclusive, rather than commercial spaces) ${ }^{1}$. The main tool used to address excessive demand is still to increase garage supply (despite its high cost), to the extent that the vast majority of parking spaces in European cities are provided by off-street parking garage facilities² (ITDP, 2010; 2011; and Rye \& Koglin, 2014).

In this context, the paper aims to study the complex role of public authority in simultaneous garage and curbside parking provision, by analyzing how both regulatory instruments interact with garage demand. It should allow public authorities to efficiently coordinate both instruments, adopt sounder parking pricing and space regulation

\footnotetext{
${ }^{1}$ Mixed use spaces are implemented in cities such as Amsterdam, London, Paris, Munich, Copenhagen, Stockholm and Chicago. Resident-exclusive schemes are implemented in London, Munich, San Francisco and Seattle (See ITDP, 2010; 2011).

2 The ratio of garage to curbside spaces is clearly above 2 , except in cities where underground parking construction would be extremely expensive (ITDP, 2010; 2011).
} 
schemes, and advise on the potential impacts of policy changes (also for private garage operators).

We provide an empirical estimation of the responsiveness of aggregate demand for garages to price and to the characteristics of curbside regulations, for both occasional parkers $^{3}$ and subscribers ${ }^{4}$. We use a panel from Barcelona's public parking authority (BSM) that covers 34 garage facilities with yearly transaction data summaries for the period 2006-2012. This method is far less data-demanding than microeconometric approaches, and it can be applied easily to other cities, regardless of their technology for gathering parking data 5 .

We find that both occasional parkers and subscribers show a similar negative elasticity to garage fares, but only occasional parkers show a clear substitution effect with a preference for on-street parking. We estimate an average curbside premium of $€ 0.55$ /hour, which supports theoretical claims that curbside fares should be set higher than garage fares (above the curbside premium, to eliminate cruising) (Arnott, 2006; and Inci \& Lindsey, 2015). This highlights the current inefficiency in the city of Barcelona's pricing scheme; that ranges between $€ 0.45$ and $€ 1.05$ per hour for users facing no discounts due to the uncoupling between curbside and garage policies. In order to bridge this gap we propose different policy options; that include a bold increase of curbside fare, a cut on garage fare and a cross-subsidy from the curb if it needs to be set below average cost.

Additionally, we find that the characteristics of space regulations have an impact on demand as well as on pricing. Commercial spaces help to shift long-term parkers to garages, but also attract occasional parkers to the curb. Mixed use spaces show no statistically significant impact on garage demand, which suggests that providing parking permits for residents does not add additional demand or shift the potential of occasional parkers towards garages. In fact, mixed use spaces slightly reduce the number of garage subscribers, and shift long-term parking to the curb.

All this stresses that the public authority should integrate curbside and garage parking into a single-market regulation approach, to overcome distortions and achieve efficiency.

\footnotetext{
${ }^{3}$ Following Tsamboulas (2001), we use the term "occasional" to describe those parkers who search for parking on the spot and pay on an hourly basis; even they can be relatively regular visitors to the area but not enough to sign a garage subscription plan (non-subscribers).
}

\footnotetext{
${ }^{4}$ Parkers who have signed a garage subscription plan payed on a monthly basis that grants them a reserved space, also described elsewhere as monthly parkers.
}

${ }^{5}$ Note that our data is gathered from the public parking authority; private operator counterparts would rarely be available. 
And it also suggests the need to consider the interactions with the private sector that might devote further research.

The paper is organized as follows. Section 2 reviews relevant literature on the issue at stake. Section 3 briefly presents the case study of Barcelona. In Section 4 we describe the methodological approach and the data used in the analysis. Section 5 presents and discusses the results of models, and Section 6 highlights the main conclusions.

\section{Literature review}

Theoretical research work has focused on the optimal curbside parking regulation problem. In recent years, relevant contributions have also been made that introduce the interaction of curbside parking regulations with garage parking in spatial competition models; see Inci (2015) for a complete review.

Spatial competition models proposed by Arnott (2006) and Inci \& Lindsey (2015) show that the full price of parking is the outcome of the interaction between garage operators and the cruising level that makes curbside and garage parking equally costly. They point out that the key to eliminate cruising by allocating excessive curbside demand to garage parking is to keep the appropriate fare differential between them. This suggests that, in the case of inelastic demand, it will be welfare-enhancing to increase curbside fares, as they do not modify the full cost of parking, but convert cruising time costs into meter revenues. Additionally, Inci \& Lindsey (2015) also suggest that efficiency can be attained regardless of the curbside fare by regulating prices in the garage sector, overcoming the localized market power issue, and even through the tacit or explicit collusion that may arise in a market where the same players interact for long periods (Froeb et al., 2003).

However, none of the previously mentioned studies took into account the role of public administration in the simultaneous provision of garage and curbside parking, and the potential competition effects this might induce in the private garage sector.

Empirical studies on parking demand have largely focused on the impact of on-street parking regulations on commuters' travel choices, using stated or revealed preference surveys; see Marsden (2006) and Concas \& Nayak (2012) for a complete review. The literature suggests that curbside parking demand is negatively related to curbside fare, but its sensitivity depends on user and trip characteristics. Curbside demand decreases with income (Gillen, 1977; Shoup \& Wilson, 1992), increases with stay duration (Khodaii et al, 2010; Kobus et al., 2013), depends on trip purpose (Kelly \& Clinch, 2006; Simicevic et al., 2012b) and increases with the level of alternative transportation modes (Hess, 2001; Weis et al., 2012). Additionally, it is expected to be non-linear and heterogeneous among demand segments (Kelly \& Clinch, 2006; Tsamboulas, 2001). Based on a metaanalysis regression, Concas \& Nayak (2012) report an average demand elasticity of - 
0.39 with respect to parking fare, which is slightly lower for the US $(-0.30)$ and much higher for non-US studies $(-0.86)$.

Only some of the most recent works take advantage of parking transaction data; see Kelly \& Clinch (2009), lbeas et al. (2011), Pierce \& Shoup (2013) and Ottosson et al. (2013), Madsen et al. (2013) and Kobus et al. (2013). And very few studies have analyzed the specific behavior of garage users, and the interactions between on-street and off-street parking regulation tools (i.e. fares, time limits, parking permits, type of spaces and their spatial distribution or the level of enforcement); see Shiftan (2002), Khodaii et al. (2010), Simicevic et al. (2012a, 2013), Tsamboulas (2001) and Kobus et al. (2013).

Kobus et al. (2013) and Simicevic et al. (2013) found that both curbside and garage parking demand are negatively related to parking fare; but only Kobus el al. (2013) reports garage demand elasticity estimates ranging from -2.2 to -1.5 for 1 hour and 20 minute stays respectively.

The substitution effect between garage and curbside parking was first empirically suggested by Kobus et al. (2013), who estimated probit models on the choice between curbside and garage parking, based on stay duration. They found that users are willing to pay a premium for on-street parking that ranges from $€ 0.37$ to $€ 0.60$ per hour, and users who park for longer durations are more sensitive to fares. Simicevic et al. (2013) reached a similar conclusion from the fact that the off-street option becomes more likely to be chosen the tighter the time limits on the curbside. This implies that even small reductions in the fare differential would greatly increase curbside demand and therefore cruising, which could be worsened by the fact that garage operators hold potentially high pricing power with inelastic parking demand, especially for short-stay trips. However, no cross-price elasticity estimates are available in the literature.

Additionally, Tsamboulas (2001) highlights that occasional garage parkers' and garage subscribers' changes in parking location and transport mode depend on a different set of criteria. This is of special relevance for garage operators as they offer parking spaces to both demand segments to make the most of their available capacity, and subscribers tend to be residents of the area who may be eligible for parking permits for the curbside.

The aim of this paper is to investigate the effects of curbside regulations' characteristics on aggregate garage parking demand, both for occasional parkers (OCC) and subscribers (SUB), and to try to combine previous findings in a single framework. This is extremely relevant for public authorities, as they need to quantify the complex interactions between parking regulation instruments in order to take policy actions. Our empirical model is fairly simplistic with low demands on data. It can be applied to any city, regardless of the level of its parking data-gathering technology. 


\section{Parking in Barcelona: context and policy}

Barcelona is the second largest city in Spain, with a population of $1.6 \mathrm{M}$ inhabitants $(4.5 \mathrm{M}$ in its metropolitan area). It is the largest Mediterranean city, and one of the most densely populated in Europe (15,900 inhab/km²). Since the 1960 s, it has experienced a process of progressive suburbanization that has increased traffic demand and associated parking needs.

Following a conventional approach, curbside regulated spaces were first introduced in 1983 to deter long stays and promote turnover in the central business district's (CBD) commercial streets, reaching 7,158 regulated parking spaces in 2004 . To promote the shift of curbside long stay parking to off-street, and to specialize curbside parking for short stays, the public authority followed a policy of increasing off-street supply by promoting the construction of 11,000 garage parking spaces between 1997 and 2004 .

Despite these measures, congestion kept increasing, which drove urban mobility towards total gridlock. The RACC (2007) estimated that congestion in Barcelona implied about $26 \mathrm{M}$ hours lost per year, equivalent to a global cost of $€ 384 \mathrm{M}$ (about $0.3 \%$ of Catalonia's GDP). In order to overcome this situation, a city-wide curbside parking regulation initiative called ÀREA was introduced in the CBD in 2005, and was extended to almost the entire city by 2009 . It was introduced as a trip deterrence measure, aimed at alleviating congestion and reducing cruising by transforming free curbside spaces to regulated spaces, and integrating all the previous on-street parking measures under a single management parking authority (BSM). It currently consists of 55,000 regulated parking spaces with dedicated uses: (i) commercial activities (blue); (ii) mixed use, including both residents and commercial parking (green); (iii) resident-exclusive (green exclusive); (iv) hauling; and (v) free spaces for motorbikes. These parking spaces are split into 22 regulatory zones covering almost the entire area of the city, with 4 fixed fare/hour bands operating during traffic peak time (i.e.: Monday to Friday $8 \mathrm{~h}-14 \mathrm{~h}$ and $16 \mathrm{~h}-20 \mathrm{~h}$ ) with a maximum stay limit (1 to 2 hours) ${ }^{6}$.

The expansion of curbside regulation has largely involved the introduction of mixed-use spaces, as these offer a virtually free parking permit to residents but charge visitors, which reduces opposition to the measure. Similar approaches have been used elsewhere, as reported by the ITDP $(2010,2011)$. This system is justified by the assumption that granting access to residents will impose further limitations on visitors (besides pricing), and push them to park off-street in a well-developed garage network. However, this somewhat contradicts both the theoretical and empirical evidence (Van Ommeren et al, 2011).

${ }^{6}$ Parking meters accept coins and credit cards, but since 2015 they have been upgraded to accept smartphone payment via App. 
The expansion of the public garage network reached a plateau with the implementation of curbside regulations, although some facilities have been completed and others are still under construction. It is interesting to note that the supply of public garages has increased twice as much as that of curbside regulated spaces. Only in recent years, the supply of public garages has been dramatically reduced after several facilities were closed due to urban transformations. Currently, BSM owns more than 100 facilities with a total supply of about 43,000 parking spaces. Following city council estimates for 2012 (no official data exists on private operators), this means that the public parking operator directly controls roughly $23 \%$ of the total public access garage supply in the city. Publicly managed garages apply a homogeneous fare/hour pricing scheme (non-progressive), regardless of their spatial location, which shows no evident linkage to on-street regulation. However, the garage subscription cost is defined at each facility.

It is also important to stress that no other relevant change in the parking sector has been detected during the ÀREA implementation, as parking minimum requirements in new constructions, broad private supply and regulation has remained the same.

\section{Methodology}

\subsection{Aggregate demand function}

We estimate an aggregate demand function using a panel data approach, where crosssection observations correspond to parking garages repeatedly observed throughout a time span. This allows us to model variations in demand resulting from policy and socioeconomic changes over time and across garage facilities.

We assume, as described in (1), that aggregate demand $\left(y_{i t}\right)$ in each parking facility $(i)$ and period of time $(t)$ is a function of garage characteristics $\left(x_{i t}\right)$, the characteristics of alternative on-street parking $\left(o_{i t}\right)$ and other neighborhood characteristics affecting car usage demand $\left(n_{i t}\right)$ within each garage facility catchment area (defined as a buffer of radius $D$ around each facility $)^{7}$, garage-specific unobserved heterogeneity $\left(\alpha_{i}\right)$ and timespecific effects $\left(\gamma_{t}\right)$ to cope with area expansions or specific shocks (i.e. economic recession). The demand function also depends on an idiosyncratic error term $\left(\varepsilon_{i t}\right)$.

As we are interested in analyzing two demand segments, namely occasional parkers who pay on an hourly basis and parking subscribers (who pay on a monthly basis), we also develop two models with slightly different variables specification, as in Tsamboulas (2001). In our case, we specify two aggregate demand functions using different

${ }^{7}$ The catchment area of each facility is defined as the area within a fixed distance buffer for each garage facility. 
aggregate demand measures. The characteristics of each of them impose the adoption of two differentiated econometric approaches: the occasional parking (OCC) model is specified as an event count model estimated by means of negative binomial specifications, adapted to panel data; whist the subscribers parking (SUB) model is estimated by least squares. The data used and each model specification are described in detail in the following subsections.

$$
y_{i t}=f\left(x_{i t}, o_{i t}, n_{i t}, \alpha_{i}, \gamma_{t}, \varepsilon_{i t}\right)
$$

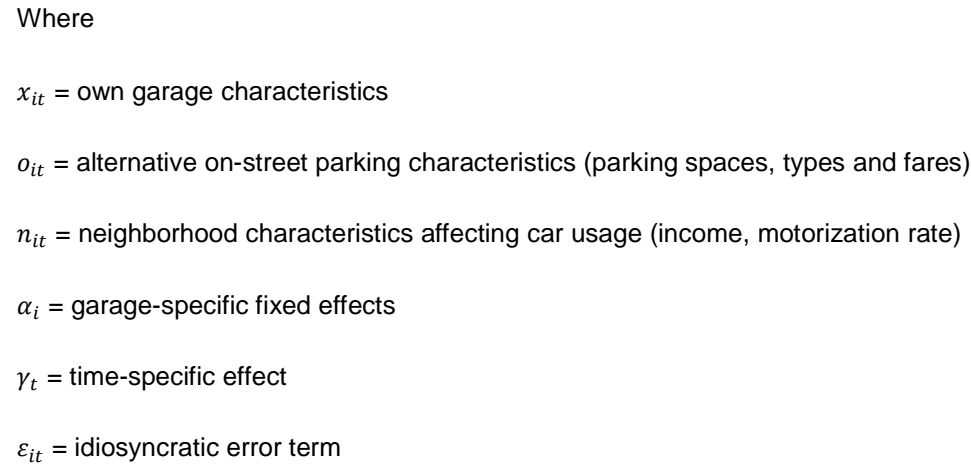

\subsection{The data}

Our dataset covers 34 of BSM's garage facilities for the period 2006-2012 (238 observations). BSM does operate some other facilities, but their demand behavior is assumed to be pretty different due to the parking policy context in their surroundings. In order to keep atypical observations out of our sample, we eliminated specific facilities that are located in the urban fringe, where ÀREA is not fully implemented and free parking is extensively available. We introduced both garage and curbside characteristics in a GIS software, which translates into a series of points that embed the information of parking regulation for each year; Figure 1 shows an example of the available data. In order to compute our explanatory variables related to curbside and neighborhood characteristics we specify the catchment areas as a buffer around each facility with a radius of 500 meters $^{8}$. The main descriptive statistics for all variables included in the OCC and SUB models are displayed in Table 1.

\footnotetext{
${ }^{8}$ We estimated the model for 500 and 800 meters ( 0.3 and 0.5 miles), following evidence reported by Lin \& Wang (2015), and the maximum acceptable outdoor walking distance described in Smith \& Butcher (1994). The results are consistent across buffers, but can be made available upon request. In this case, we only report the results for the 500 -meter buffers, as this distance is
} 


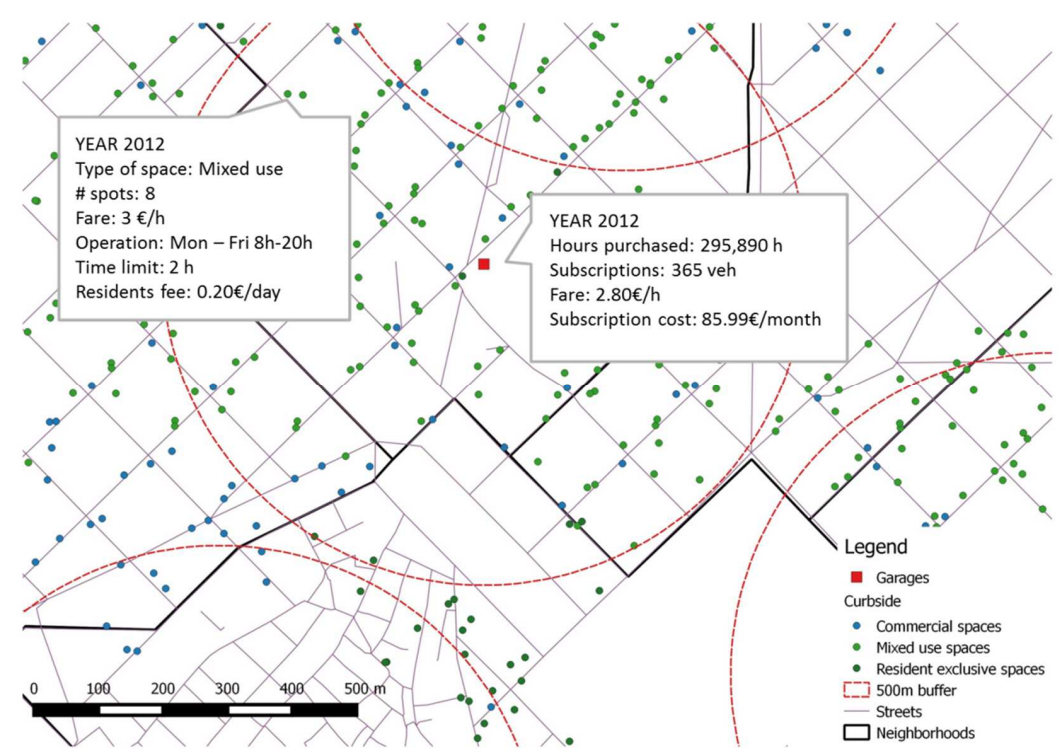

Figure 1. Detail of the information integrated in a GIS software to compute explanatory variables within $500 \mathrm{~m}$ buffer around each garage facility in the sample.

The dependent variable for the OCC model is garage parking demand at each garage facility, measured as yearly purchased parking hours $\left(H_{i t}\right)$ at each facility $(i)$ and period $(t)$; made available in BSM parking facilities' annual reports. The latest studies using parking transaction data tend to define demand by occupancy rate (Ottosson et al., 2013; Madsen et al., 2013). However, we believe that yearly purchased parking hours is a better demand indicator in our case. The fact that occasional parkers and subscribers share the same facility raises awareness about the validity of occupancy rate changes to measure demand changes, as parking subscribers purchase the right to park in advance, and thus their parking spaces are unavailable to other users, whether they park or not. Additionally, yearly purchased parking hours can be used to directly compute occupancy rates, revenues and changes in average stay length.

It has to be noted that this dependent variable specification does not follow a normal distribution, but a negative binomial one. The preponderance of relatively small numbers suggests that the regression approach can be improved by using the event count method, which takes into account the issue of overdispersion (negative binomial), as the variance for $\mathrm{H}$ is far higher than its mean.

generally used by practitioners as a rule of thumb for the catchment area. Additionally, note that the minimum feasible radius is constrained to the existence of sufficient variation in the data. 


\begin{tabular}{|c|c|c|c|c|c|}
\hline & \multicolumn{5}{|c|}{ Std. Dev. } \\
\hline Variable & Mean & Overall & Between & Within & Source \\
\hline $\mathrm{H}$ & 207528.50 & 192055.40 & 188200.70 & 48605.20 & BSM \\
\hline VEH & 281.30 & 119.84 & 116.54 & 33.55 & $"$ \\
\hline GF & 1.72 & 0.25 & 0.20 & 0.14 & $"$ \\
\hline GS & 98.66 & 22.59 & 22.44 & 4.41 & $"$ \\
\hline CPS & 218.58 & 133.38 & 130.20 & 35.60 & $"$ \\
\hline MPS & 661.31 & 538.57 & 502.65 & 209.27 & $"$ \\
\hline RPS & 148.56 & 285.04 & 287.17 & 29.42 & $"$ \\
\hline FPS & 138.55 & 301.69 & 190.00 & 236.29 & $"$ \\
\hline RF & 2.49 & 0.21 & 0.17 & 0.13 & $"$ \\
\hline POB & 22570.68 & 10172.79 & 10287.97 & 568.25 & BCN Stat.Dept. \\
\hline RCAR & 354.18 & 83.93 & 83.33 & 16.58 & $"$ \\
\hline LANDV & 403.59 & 122.69 & 105.12 & 65.45 & DTES Gencat \\
\hline
\end{tabular}

Table 1. Summary of descriptive statistics, information source, and expected signs in OCC and SUB models

In the SUB model we measure garage parking demand as the number of 24 equivalent parking contracts subscribed $\left(V E H_{i t}\right)$, as there are different subscription modalities that allow parking access at different times (day, noon, overnight and weekends). In this case, changes in occupancy rate provide no information about subscribers' demand, as we are interested in how many parkers want to buy the right to parking spaces for a certain period of time, not how long they stay each time. This figure follows a normal distribution, and can be found in the annual reports of BSM parking facilities (only in aggregate terms).

The characteristics of the garages are also extracted from the BSM parking facilities' annual reports. Garage fare $\left(G F_{i t}\right)$ is measured as the average hourly fare by computing the ratio between yearly revenue raised from short stay vehicles and yearly purchased parking hours (including cash-in advance options). The fact that the public authority has adopted a city-wide garage pricing scheme eliminates a possible endogeneity issue, as the garage parking fare does not change in response to garage demand.

Subscription cost $\left(G S_{i t}\right)$ is measured as the average monthly subscription by computing the ratio between the yearly revenue raised from long stay vehicles and the yearly number of subscribed vehicles, divided by 12 months. Unlike garage fares in the OCC model, garage subscription costs do not follow a uniform pricing scheme. However, the correlation coefficient between the log of subscription cost and the log number of subscribers is only 0.11 , which suggests that there is no special problem of endogeneity.

We assume that demand is only affected by on-street parking characteristics within a garages' potential catchment area (D). Thus, alternative parking supply is captured by the number of free $\left(F P S_{i t}\right)$, commercial $\left(C P S_{i t}\right)$ and mixed use parking spaces $\left(M P S_{i t}\right)$ within the 500-meter catchment area. For facilities where ÀREA was initially not fully implemented, free parking supply is computed as the difference between the maximum total number of parking spaces before the ÀREA extension and the regulated supply. 
After full extension, it is set to 1 , in order to avoid problems with the log specification, even it was set to zero as all free parking was eliminated.

The on-street parking fare $\left(R F_{i t}\right)$ is computed as the weighted average fare for commercial and mixed use spaces within the catchment area. The SUB model additionally includes resident-exclusive parking spaces $\left(R P S_{i t}\right)$ within the 500-meter buffer around each facility.

All these figures are conveniently estimated using geographic information systems (GIS) software, based on BSM data maps ${ }^{9}$ and BSM (2013). The inclusion of garage-specific fixed effects controls for the endogeneity of the on-street fare, as garage demand may be high where on-street demand and fares are also high. However, this still excludes the case where changes in the on-street fare over time are a response to garage demand changes. As long as these adjustments in prices are a political decision rather than a response to demand changes, we find our previous assumption to be valid, as stated in Madsen et al. (2013).

In order to cope with a neighborhood's time-varying characteristics, we computed the number of thousands of inhabitants $\left(P O P_{i t}\right)$ within the catchment area. This figure is computed as the neighborhood-weighted average population with a weight proportional to the neighborhood area, overlaid with the 500-meter buffer for each BSM garage, using GIS software. This is obviously a proxy for the number of residents in the catchment area, as it assumes that population is uniformly distributed in each neighborhood. This assumption is fairly reliable for all neighborhoods except the city fringe (facility locations from this area are not included in our sample).

The same procedure has also been applied to account for the density of cars $\left(R C A R_{i t}\right)$ per thousand of inhabitants registered within each buffer. Additionally, we introduce the average real estate selling price $\left(L A N D V_{i t}\right)$ in thousands of euros ${ }^{10}$ at district level as a proxy for income. All previous neighborhood figures are reported by Barcelona City Council's statistics department.

Other neighborhood characteristics that affect parking demand and vary over facilities but remain fixed over time, such as economic activity or commercial areas, are assumed to be captured by garage-specific fixed effects $\left(\alpha_{i}\right)$. However, some intrinsic catchment area characteristics that affect long stay parking demand are not fixed and may vary randomly, for example, the amount of private parking that is available. Additionally, we

\footnotetext{
${ }^{9}$ Previous data maps were provided by BSM. The current version of this map is available at the ÀREA web page: http://www.areaverda.cat/en/map/

${ }^{10}$ All monetary units are expressed in current terms.
} 
include a time-specific effect $\left(\gamma_{t}\right)$ to explore possible ÀREA expansion effects, any potential time trend, or specific shocks affecting demand (such as economic recession).

\subsection{Model specifications}

In the occasional parkers (OCC) model, the aggregate demand function dependent variable is defined as yearly parking purchased hours $\left(H_{i t}\right)$. We specify this variable using negative binomial regression ${ }^{11}$ with a common log-linear specification for the $\lambda_{i t}$ parameter and explanatory variables as expressed in $(2)^{12}$. The estimated parameters in (2) can be interpreted as demand semi-elasticities.

In the subscribers' parking (SUB) model, the aggregate demand function dependent variable is defined as the number of vehicles or parking contract subscribers $\left(V E H_{i t}\right)$, specified in a log-linear ${ }^{13}$ form with explanatory variables as depicted in (3). Least squares estimated parameters are interpreted as demand elasticities.

In order to account for unobserved heterogeneity, we estimate fixed (FE) and random effects (RE) specifications for both models ${ }^{14}$. To choose between them, we check for the correlation between unobserved heterogeneity and the regressors, using the Hausman test. All the previous models' specifications are estimated using cluster-robust standard errors, with clustering on the garage facilities to control for the remaining heteroskedasticity and serial correlation within facilities.

We estimate both OCC and SUB models with the parking regulation and neighborhood characteristic variables for a 500-meter buffer around each garage facility. The aim is to analyze the interactions between garage demand and curbside regulation, and check the area around each garage for which it is relevant.

\footnotetext{
${ }^{11}$ We also estimated the Poisson counterparts of these models, but the Lagrange Multiplier test allows us to reject the null of no overdispersion. The need to consider unobserved heterogeneity either by NBFE or NBRE is confirmed by the LR test.

12 See Hausman et al. (1984) for further detail on the negative binomial regression specification

${ }^{13}$ We tested three alternative functional forms and decided on goodness of fit (log-likelihood). Additionally, log-linear functional form was adopted in similar empirical works, such as Ottoson et al. (2013).

14 The need to consider garage-specific effects is highlighted by a joint significance test with a null hypothesis of equality between all garage-specific dummies' coefficients.
} 


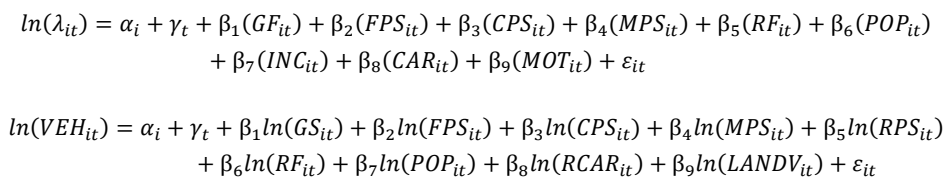

where:

$\alpha_{i}=$ garage-specific fixed effects

$\gamma_{t}=$ time-specific effect

$H_{i t}=$ number of yearly purchased parking hours (in facility $i$ and period $t$ )

$V E H_{i t}=$ number of parking contract subscribers (in facility $i$ and period $t$ )

$G F_{i t}=$ weighted average garage parking fare $(€ / \mathrm{h})$

$G S_{i t}=$ weighted average garage subscription cost $(€ /$ month $)$

$C P S_{i t}=$ number of commercial use parking spaces within $\mathrm{D}$

$M P S_{i t}=$ number of mixed use parking spaces within $\mathrm{D}$

$R P S_{i t}=$ number of resident-exclusive parking spaces within $\mathrm{D}$

$F P S_{i t}=$ number of free parking spaces within $\mathrm{D}$

$R F_{i t}=$ on-street weighted average parking fare within $\mathrm{D}$

$P O P_{i t}=$ number of inhabitants within $\mathrm{D}$

$R C A R_{i t}=$ ratio of cars per inhabitant within $\mathrm{D}$

$L A N D V_{i t}=$ average real estate selling price $(€)$ within $\mathrm{D}$

\section{Results and discussion}

In this section, we present and discuss the results for the demand functions estimated for the two demand segments: occasional parkers (OCC) and parking subscribers (SUB). As all tests indicate a preference for the fixed-effects model, we only show its results for both models ${ }^{15}$. Additionally, to facilitate the comparison between both demand segments,

\footnotetext{
${ }^{15}$ In order to choose between fixed-effect and random-effects, the Hausman test is computed for both models. In the case of OCC, the test indicates the rejection of the null of no correlation between unobserved heterogeneity and the regressors $(H=15.48$ with a $p$-value lower than 0.03$)$, which suggests that NBFE should be used as it is surely consistent. A similar conclusion can be
} 
we also report the elasticities at mean values for both models. All these figures are shown in Table 2.

In this Table, we can see that both OCC and SUB demands are negatively related to the garage fare/hour (GF) and the monthly subscription cost (GS), respectively. For OCC, a $1 € /$ hour increase in garage fare yields a $69 \%$ reduction in the number of purchased parking hours, which translates into an average elasticity at the mean of -1.19 . In a similar way, the elasticity of SUB demand to monthly subscription cost across buffers is -1.11 . If we compare the estimated coefficients, we can see that both OCC and SUB demands are fairly elastic, and below the estimates reported by Kobus et al. (2013) for an average stay of 1.2 hours, but in the upper bound of the range reported for curbside demand by Concas \& Nayak $(2012)^{16}$.

Using a z-test, we checked the null hypothesis that the coefficients for OCC and SUB are equal. This result does not appear to agree with Tsamboulas's (2001) finding that subscribers' response to the fare differential is twice that of occasional parkers. However, Tsamboulas's estimates refer to a change in parking location when occasional parkers really can reduce their parking duration, park elsewhere, shift mode or desist from travelling. In contrast, subscribers are unlikely to change parking duration, avoid traveling or change transport mode as their trip is very frequent and probably highly constrained, leaving only a change in parking location as a feasible option. This reasoning suggests that the impact on aggregate demand can plausibly be of the same magnitude, as we report.

Interesting differences arise in curbside parking spaces, as both demand segments show quite different sensitivities to the types of regulated spaces. OCC demand is negatively related with the number of commercial spaces (CPS), with an estimated elasticity at the mean of -0.27 . In contrast, commercial spaces show a positive relation with SUB demand of +0.13 . This suggests that commercial spaces act as a curbside substitute for occasional garage parking, but act as a curbside constraint for subscribers. This opposite effect in each garage demand segment should be taken into account by public authorities when they change curbside regulations, as it might transfer demand to the curb and alter garage revenues.

Changing the provision of mixed use parking spaces has no statistically significant impact on OCC or SUB demand at any given buffer. The widespread extension of this particular type of spaces has been justified by the assumption that resident parking

drawn for the SUB $(H=35.68$ with a $\mathrm{p}$-value lower than 0.01$)$. Alternative estimation results can be made available upon request.

${ }^{16}$ In their sample, average fare elasticity was -0.48 , with a standard deviation of \pm 0.65 . If we only consider non-US studies with higher average price elasticities $(-0.69)$, the range is expanded. 
permits act as an additional constraint to occasional parkers, and might help to shift demand to off-street facilities, regardless of the pricing strategy. Our results clearly do not backup this assumption. We hypothesize that residents' monopolization of the use of these spaces translates into more cruising, while commercial spaces can further help to shift demand towards garages.

\begin{tabular}{|c|c|c|c|}
\hline \multirow[b]{2}{*}{ Variables } & \multicolumn{2}{|c|}{ OCC } & \multirow{2}{*}{$\begin{array}{l}\text { SUB } \\
(3)\end{array}$} \\
\hline & (2) & $\left(2^{\prime}\right)$ & \\
\hline GF & $\begin{array}{c}-0.695 * * * \\
(0.0780)\end{array}$ & -1.195 & \\
\hline GS & & & $\begin{array}{c}-1.109 * * * \\
(0.290)\end{array}$ \\
\hline MPS & $\begin{array}{c}-2.68 \mathrm{e}-05 \\
(7.69 \mathrm{e}-05)\end{array}$ & $n / s$ & $\begin{array}{l}-0.00495 \\
(0.0303)\end{array}$ \\
\hline CPS & $\begin{array}{c}-0.00124 * * * \\
(0.000306)\end{array}$ & -0.271 & $\begin{array}{l}0.132 * * \\
(0.0508)\end{array}$ \\
\hline RPS & & & $\begin{array}{l}-0.0546^{*} \\
(0.0245)\end{array}$ \\
\hline FPS & $\begin{array}{l}-0.000108 \\
(7.39 e-05)\end{array}$ & -0.014 & $\begin{array}{l}-0.0102^{*} \\
(0.00421)\end{array}$ \\
\hline $\mathrm{RF}$ & $\begin{array}{c}0.308^{* * *} \\
(0.119)\end{array}$ & 0.768 & $\begin{array}{l}-0.100 \\
(0.776)\end{array}$ \\
\hline POP & $\begin{array}{c}-1.12 \mathrm{e}-05 \\
(8.96 \mathrm{e}-06)\end{array}$ & $n / s$ & $\begin{array}{c}1.118^{* * *} \\
(0.191)\end{array}$ \\
\hline RCAR & $\begin{array}{l}-0.000347 \\
(0.000666)\end{array}$ & $n / s$ & $\begin{array}{c}0.734 * * \\
(0.201)\end{array}$ \\
\hline LANDV & $\begin{array}{c}0.000607 * * \\
(0.000287)\end{array}$ & 0.244 & $\begin{array}{l}0.190 * * \\
(0.0736)\end{array}$ \\
\hline Constant & $\begin{array}{c}5.015^{* * *} \\
(0.497) \\
\end{array}$ & & $\begin{array}{c}-6.356 * * \\
(2.541)\end{array}$ \\
\hline Obs. & 238 & & 238 \\
\hline R2 & & & 0.22545943 \\
\hline $\mathrm{F}$ & & & 28863381 \\
\hline LL & $-22,674,052$ & & \\
\hline Chi2 & 32846132 & & \\
\hline
\end{tabular}

Table 2. Estimated demand equations for OCC and SUB models. For the OCC model (2), reports estimated semielasticities and (2') the elasticities at mean values. For the SUB model (3), reports estimated elasticities. Standard errors are reported in parenthesis. *, ${ }^{* *}$ and ${ }^{* * *}$ denote significance at $10 \%, 5 \%$ and $1 \%$ respectively. Time dummies are not reported.

Changes in the provision of free parking spaces negatively affect SUB garages' demand, with an estimated elasticity of -0.01 . The fact that we found no relevant impact on OCC does not mean that increasing the number of free spaces does not potentially undermine the demand for garages, as it is expected that occasional parkers are far more sensitive to walking time (Tsamboulas, 2001). This suggests that occasional parkers will only be affected by changes in the provision of free parking within an acceptable walking distance, which we assume from our results will be far less than $500 \mathrm{~m}$ to the garage facility. 
Additionally, resident-exclusive spaces (RPS) do show a negative relation with subscribers' parking demand, with estimated elasticities of -0.05 (higher than the response to FPS) ${ }^{17}$. This confirms that residents represent a relevant share of garage subscribers, and suggests that granting parking permits to residents does undermine the shift of long stay parking to off-street facilities.

The curbside weighted average regulated fare also has a different impact on both demand segments. We find positive cross-elasticity for occasional parkers, as a $€ 1$ increase in curbside fee shifts $31 \%$ of demand to garage parking, which is equivalent to 0.77 elasticity at mean values. This indicates a clear substitution effect between curbside and garage parking, as previously suggested in Kobus et al. (2013), even though there are no cross-elasticity estimates to compare ours with.

Additionally, the fact that cross-elasticity is below own-elasticity suggests that the curbside might be preferred to garage parking. Computation of the ratio between garage and curbside fee semi-elasticities in OCC yields a curbside premium of $€ 0.55^{18}$, which is in line with the figures reported in Kobus et al. (2013). This is of special relevance in the case of Barcelona, as garage parking fares are systematically higher than curbside fares. Our finding suggests that in 2012 pricing efficiency gap for the users that face no garage fare discount can range between $€ 0.45$ and $€ 1.05$ depending on the area, the type of space, and the associated fare scheme implemented around each garage facility ${ }^{19}$; as shown in Figure 1. This is the case as BSM applies a uniform garage parking fare policy, in fulfillment of the political agreement reached by city council 20 ; which also sets fare increases indexed to CPI. These measures translated into uniform fares have usually been justified by policy makers on the grounds of fairness and equity. However, this mismatch between curbside and garage pricing regimes shows the uncoupling in the political perception of such substitutive goods. This is highlighted by the fact that onstreet and off-street parking fares are set by independent political agreements and public authority manages both as separate business units (with their own operating accounts).

17 Note that RPS is not included in the OCC model as these spaces are restricted only to residential parking, and no alternative is available for occasional parkers.

18 Equating the demand changes induced by a $€ 1$ curbside fare increase with respect to a $€ 1$ increase in the garage fare, we obtain the proportional valuation of one over the other. The remaining part up to equivalent valuation is assumed to be the curbside premium $\left(1-\beta_{5} / \beta_{1}\right)$ per each euro increased.

19 The price efficiency gap we provide is computed by subtracting curbside average weighted fare to the regular garage fare per hour with no discounts $(2.80 € / \mathrm{h}-\mathrm{RF})$; then adding up the estimated curbside premium $(0.55 € / h)$. Note that regular users that purchase a garage pass with discount fares will face much lower gap.

${ }^{20}$ City Council Agreement adopted by the Mobility and Security Comission on July 12th 2007. 
In this regard we would recommend the public authority to follow a non-homogeneous and coordinated curbside and garage parking pricing scheme.

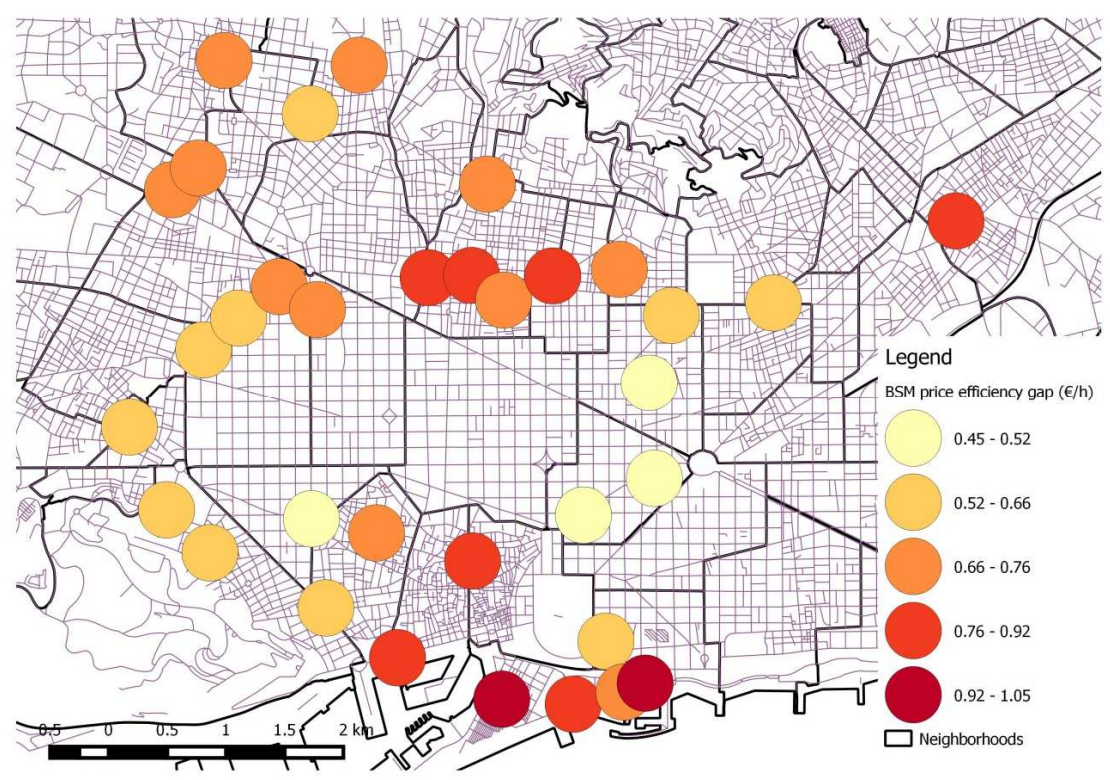

Figure 2. Price efficiency gap for the garage facilities included in our sample in 2012 (Computed as the difference between GF and RF plus the proxied curbside premium).

The price efficiency gap highlights the key role of a garage versus curbside fare differential in parking regulations, as relative reductions in curbside fare will transfer users towards the curb, reducing performance and increasing associated externalities. This stresses the need for the public authority to undertake a single integrated market regulation approach. To correct the price efficiency gap public authority can either increase curbside price, reduce public garage prices or chose some middle ground combination of both. We would recommend public authority to equate garage prices to marginal cost and increase curbside price up to a premium above garage prices. If this curbside price increases is politically unfeasible we would recommend to explore the option to increase curbside price as much as possible and reduce garage price below marginal cost, setting a cross subsidy between the curb and garages as suggested in Arnott (2006).

It is relevant to highlight that the price efficiency gap issue is even bigger for the private garage sector, as public garages are on average about $8 \%$ cheaper (BSM, 2013). Public authority needs to include private sector on its integrated market regulation approach, otherwise private operators might act strategically taking advantage of curbside price increases and the impact of policy intervention would be hampered. Inci \& Lindsey (2015) 
suggest that efficiency can be reached by regulating private sector prices; however this kind of regulation would be highly unlikely due to political constraints. In a market with high sunk cost and long assets time span this type of change in regulation will translate into a major cut in profitability that will imply a strong opposition, discouraging private investment and compromising off-street garage supply. Thus, we would rather recommend the public authority to explore the introduction of competition to discipline private sector prices. And taking into account that a cross-subsidy might be welfare enhancing it might also be advisable to explore potential public-private partnerships that link curbside management to garage concessions. However, the interaction between public and private agents in this market is not well stablished and needs further research.

Additionally, this substitution effect also endorses the dependence between garage and curbside demand. According to our estimates, it cannot be neglected, as also stated in Madsen et al. (2013). This indicates the need to further develop existing curbside transaction data demand models to simultaneous curbside and garage modelling for occasional parkers; an approach that has not yet been taken into account in the empirical literature (Ottosson et al., 2013; Madsen et al., 2013; and lbeas et al., 2011). This is very relevant as all previous parking demand elasticity estimates are potentially biased (including the ones we report).

However, the curbside fare has no statistically significant impact for subscribers, which indicates that there is no substitution effect for this demand segment between on-street and off-street. This is in line with Khodaii et al. (2010) and Kobus et al. (2013), as short stay parkers are more sensitive than long stay users. However, our results go one step further and indicate that garage subscribers are not sensitive at all. This additionally suggests that subscribers and occasional parkers might be pretty independent demand segments. But yet, even we do not consider it in this paper, an issue that needs further consideration is the fact that subscribers might find closer substitutes in off-street private parking supply (monthly rents) which will be affected by parking minimum requirements, private parking office availability and specific regulations.

All this shows that curbside parking regulations are a relevant determinant of garage demand, and public authorities should make an effort to manage them as a single system. Our results indicate that the way curbside parking spaces are regulated (parking allowance and time limits) has a considerable impact. Reducing the total supply of curbside spaces will shift occasional parkers to garages; even curbside fare policy is an even more efficient trigger for behavioral change. This advocates for shifting Barcelona's actual parking policy to embrace pricing full potential implementing more complex schemes (Shoup, 2005). If the goal is to shift cars from on-street to off-street parking while ensuring cost recovery, then the proper combination of pricing and spaces in the policy can help to achieve this. 
Finally, OCC and SUB models differ in the impact of neighborhood characteristics on aggregate demand. The population (POB) shows no statistically significant relation with OCC, which could be due to the fact that occasional parkers do not need to reside in the garage area. In contrast, as expected SUB is strongly positively related to population, as residents are probably the largest group of users in need of a parking subscription.

The car ownership ratio (RCAR) is only positively related to SUB, with an estimated elasticity in the number of cars per inhabitant of 0.73 . This shows that car ownership changes are an important driver of parking subscriptions. As expected, OCC shows no statistically significant relation with the car ownership ratio, as occasional parkers' demand is mainly driven by visitors.

Land value changes (LANDV) do show a positive relation with OCC and SUB of about the same magnitude, even though the interpretation of the meaning of this variable in each case is different. OCC estimated elasticity at mean values is about 0.24 , which could capture the type of economic activities that take place in the area (unobservable for us), suggesting the need to further consider the spatial distribution of economic activity. However, SUB estimated elasticity is 0.19 , which is in line with the range of estimates reported by Gillen (1977).

\section{Conclusions}

The impact of curbside parking regulation on garage parking demand is investigated in this paper. Specifically, we analyze the aggregate demand behavior of two demand segments: occasional (OCC) and subscribers' parking (SUB). Two econometric models are proposed, one for each of these demand segments. The aggregate demand functions of the OCC and SUB models are estimated using a panel from Barcelona's public parking authority (BSM) that covers 34 garage facilities with yearly data for the period 2006-2012. The OCC model is specified as an event count model estimated by means of negative binomial specifications, and the SUB model is estimated by least squares adapted to panel data; both accounting for garage-specific fixed effects and time-specific shocks. This method is far less data-demanding than existing microeconometric approaches and it can be easily applied to any cities, regardless of their parking data-gathering technology; where only enough yearly summaries need to be available.

This approach allows us to provide the first empirical estimates reported in the literature for garage demand responsiveness by segments (occasional parkers and subscribers). Our estimates show that both garage demand segments are fairly responsive to their own price, with elasticities close to the curbsides' upper bound figures. Both occasional parkers and subscribers of garages show the same sensitivity to garage fare and subscription cost, respectively. 
Regarding curbside pricing interaction, we find that occasional parkers show high curbside fare cross-elasticity; while subscribers hold no statistically significant relation. This indicates a clear substitution effect between curbside and garage parking for occasional parkers. Whether subscribers might find closer substitutes in off-street private parking supply (monthly rents) or not, which will be affected by parking minimum requirements, private parking office availability and specific regulations, will need further research as it is beyond the purpose of our analysis.

The fact that the cross-elasticity for occasional parkers is below own-elasticity suggests that the curbside might be preferred to garage parking (curbside premium). All this highlights the key role of a fare differential between curbside and garage to achieve efficient parking demand allocation, and the relevance of undertaking an integrated curbside/garage market management approach, as already claimed in theoretical works (Arnott, 2006; Inci \& Lindsey, 2015). In our specific case, the estimates also show the huge pricing efficiency gap that exists in Barcelona, driven by a homogeneous public garage parking fare policy and uncoupling between curbside and garage regulation.

Regarding regulations on curbside spaces, we find that both demand segments show quite different sensitivities to the types of regulated spaces. OCC demand is negatively related to the number of commercial spaces, while the relation with subscribers is positive. This suggests that commercial spaces act as a curbside substitute for occasional garage parking, but act as a curbside constraint for subscribers.

Mixed use spaces have no statistically significant impact on OCC or SUB demand at any given buffer, which contradicts the common assumption used to justify these spaces, as resident permits do not seem to lead to any additional demand shift from the curb to garages (as in the case of commercial spaces). The provision of free and residentexclusive parking spaces has a small, negative effect on subscribers' demand, while occasional parkers show no response, presumably due to the comparatively higher walking cost.

All this shows that curbside parking regulations are a relevant determinant of garage demand, and public authorities should make an effort to manage the curbside/garage parking market as a single system. Our results show that the characteristics of curbside parking spaces (allowance and time limits) and the pricing strategy play a role in garage demand determination, with relevant differences between demand segments. Curbside fare policy is an even more efficient trigger for behavioral change, and the proper combination of pricing and spaces policy needs to be applied to avoid counterbalancing its effects. Thus, the development of future parking pricing schemes must take into account curbside and garage interactions. 


\section{AKNOWLEDGMENTS:}

The authors wish to thank BSM for providing access to the dataset, especially to Òscar Puigdollers, Carlos Morillo and Victor Jodar for their work, implication and policy insights. All remaining errors are the author's responsibility. This study received support from the Spanish Government - project ECO2012-38004 - and from the Regional Government of Catalonia - project SGR2014-325 


\section{References}

Arnott, R. (2006) Spatial competition between parking garages and downtown parking policy, Transport Policy, 13, 458-469.

BSM (2013) Estudi de les tarifes d'abonaments i rotació dels aparcaments públics localitats a la zona regulada, Barcelona de Serveis Municipals (BSM,SA.)

Button, K. (2006) The political economy of parking charges in "first" and "second-best" worlds, Transport Policy, 13, 470-478.

Concas, S. \& Nayak, N. (2012) A Meta-Analysis of Parking Price Elasticity, In Proceedings of the TRB Annual Meeting. 2012: Washington, DC.

Froeb, L.; Tschantz, S. \& Crooke, P. (2003) Bertrand competition with capacity constraints: mergers among parking lots, Journal of Econometrics, 113, 49-67.

Gillen, D.W. (1977) Estimation and Specification of the Effects of Parking Costs on Urban Transport Mode Choice. Journal of Urban Economics, 4, 186-199.

Hausman, J. A.; Hall, B. H. \& Griliches, Z. (1984) Econometric models for count data with an application to the patents-R \& D relationship, Econometrica, 52, 909-938.

Hess, D.B. (2001) The Effects of Free Parking on Commuter Mode Choice: Evidence from Travel Diary Data, Transportation Research Record, 1753, 35-42.

Ibeas, A.; Cordera, R.; dell'Olio, L. \& Moura, J.L. (2011) Modelling demand in restricted parking zones, Transportation Research Part A, 485-498.

Inci, E. (2015) A review of the economics of parking, Economics of Transportation, 4(12), 50-63.

Inci, E. \& Lindsey, R. (2015). Garage and curbside parking competition with search congestion, Regional Science and Urban Economics, 54, 49-59

Ison, S.G. (2014) Parking management policy: its potential in improving urban traffic flows, 21st ACEA Scientific Advisory Group Report.

ITDP (2010) US parking policies: An overview of management strategies, Institute for Transportation and Development Policy, New York, USA.

ITDP (2011) Europe's parking U-turn: From accommodation to regulation, Institute for Transport and Development Policy, New York, USA.

Kelly, J.A. \& Clinch, J.P. (2006) Influence of varied parking tariffs on parking occupancy levels by trip purpose, Transport Policy, 13, 487-495. 
Kelly, J.A. \& Clinch, J.P. (2009) Temporal variance of revealed preference on-street parking price elasticity, Transport Policy, 16, 193-199.

Khodaii, A.; Aflaki, E. \& Moradkhani, A. (2010) Modeling the Effect of Parking fare on personal car use, Transaction A: Civil Engineering, 17, 209-216.

Kobus, M.B.W.; Guitiérrez-i-Puigarnau, E.; Rietveld, P. \& Van Ommeren, J.N. (2013) The on-street parking premium and car drivers' choice between street and garage parking, Regional Science and Urban Economics, 43, 395-403.

Lin, H. \& Wang, Y. (2015), Competition and price discrimination: evidence from the parking garage industry, Journal of Industrial Economics, 63(3), 522-548.

Litman, T. (2006) Parking Management Best Practices, Planners Press.

Madsen, E.; Mulalic, I. \& Pilegaard, N. (2013) A model for estimation of the demand for on-street parking, MPRA Paper No. 52301, Technical Univeristy of Denmark, Denmark.

Marsden, G. (2006) The evidence base for parking policies: a review, Transport Policy, 13(6), 447-457.

Ottosson, D.B.; Chen, C.; Wang, T. \& Lin, H. (2013) The sensitivity of on-street parking demand in response to price changes: A case study in Seattle, Transport Policy, 25, 222232.

Pierce, G. \& Shoup, D.C. (2013) Getting the prices right, Journal of the American Planning Association, 79, 67-81.

RACC (2007) La congestión en los corredores de acceso a Barcelona, Fundación Real Automóvil Club de Catalunya (RACC), Barcelona.

Rye, T. \& Koglin, T. (2014) Parking Management; In: Ison, S. \& Mulley, C. (ed.) Parking Issues and Policies (Transport and Sustainability, Volume 5) Emerald Group Publishing Limited.

Shiftan, Y. (2002) The effects of parking pricing and supply on travel patterns to a major business district; In: Stern, E., Salomon, I., Bovy, P.H.L. (Eds.), Travel Behaviour: Spatial Patterns, Congestion and Modelling. Edward Elgar Publishing, Cheltenham, UK.

Shoup, D.C. \& Wilson, R. (1992) Employer-Paid Parking: The Problem and Proposed Solutions, Transportation Quarterly, 46, 169-196.

Shoup, D.C. (2005) The High Cost of Free Parking, Chicago: Planners Press.

Simicevic, J.; Milosavljeciv, N. \& Maletic, G. (2012a) Influence of parking price on parking garage users' behavior, Promet - Traffic\&Transportation, 24, 413-423. 
Simicevic, J.; Milosavljeciv, N.; Maletic, G. \& Kaplanovic, S. (2012b) Defining parking price based on users' attitudes, Transport Policy, 23, 70-78.

Simicevic, J.; Vukanovic, S. \& Milosavljeciv, N. (2013) The effect of parking charges and time limit to car usage and parking behaviour, Transport Policy, 30, 125-131.

Smith, M. \& Butcher,T. (1994) How far should parkers have to walk? Parking, 47, 28-31.

Tsamboulas, D.A. (2001) Parking fare thresholds - a policy tool, Transport Policy, 8, 115124

Van Ommeren, J.; Wentink, D. \& Dekkers, J. (2011) The real price of parking policy, Journal of Urban Economics, 70, 25-31.

Weis, C.; Vrtic, M.; Widmer, P. \& Axhausen, K.W. (2012) Influence of Parking on Location and Mode Choice: A stated choice survey, In Proceedings of the $91^{\text {st }}$ TRB Annual Meeting, Washington, $D C$. 